\title{
1. Internet technology as a global connector
}

Since the beginning of the twenty-first century, an emerging new global economy has been created in part by the merger of powerful computing devices with the internet. Growth has accelerated with the fusion of information and communication technologies (ICTs), permanently altering how businesses, individuals, governments, and educational institutions interact. Whether we ignore, oppose, or support it, globalization is having a significant impact on the roles and responsibilities of business, education, government, and society. In this chapter, we focus on education as a driver of economic development, highlighting growing interdependencies, and the consequences of globalization for individuals and institutions.

What was viewed a generation ago as a controlled and gradual shift in knowledge management processes has increased from a trickle to a torrent of new communication devices, information sources, and internet connections. Generally referred to as globalization, these forces increase the speed at which goods and services - and more recently information, ideas, three-dimensional (3D) replicas, and people - flow across international borders. As a consequence, nearly every institution in modern societies (and many in rapidly developing ones) is flooded with new data sources, and technologies accessible on faster servers with wider internet bandwidths. These borderless mega-trends are reshaping how individuals and institutions engage in commercial, political, professional, and social relationships. The availability of cheaper internet connection devices, such as cellphones that work like mini-computers for distance education in developing countries, opens the door wider for educational applications in populations to whom access was formerly closed (Porter et al., 2016). The terms "digital learning," "e-learning," "virtual learning," and "distance learning" are used interchangeably throughout this book and refer to the same basic concept: "a method of learning in which the learner is physically separated from the teacher and the institution sponsoring the instruction" (Mielke, 1999). 


\section{CONTRASTING VIEWS OF GLOBALIZATION}

Expanded access to and application of new ICTs marks a fundamental shift in the age-old process of exchanging knowledge, a fundamental purpose of education. The availability of less expensive and more powerful connection devices - laptops, mini-computers, tablets, and smartphones - enables direct face-to-face contact between individuals from almost anywhere in the world. These exchanges take place instantly, and generally without interference from intermediaries such as corporations or government (with the well-known exceptions of national intelligence agencies and China's Great Firewall). Americans may not be as censored by the state as citizens from other countries, but that does not mean that United States (US) citizens can assume that the information found online is not manipulated in some way. We would like to think that the information on the internet is unadulterated, yet search engine results and unsolicited ads are tailored to our profiles, and prices changed based on internet protocol (IP) addresses, hardware profiles, and zip codes. Nonetheless, for the first time in human history, billions of people in geographically isolated regions of the world are able to access, connect, and exchange information once held exclusively by clergy, nobility, and economic elites. Everyone with an internet access device possesses the capacity to add to the treasure trove of human knowledge as no previous generation has ever been allowed to.

The perceived democratization of access to information may not be a welcome trend for all stakeholders. Information is power, and its control has been recognized as a means to subjugate people by elites since the establishment of recorded history. With its open access potential to share information, the internet can be a dangerous space; rapid changes in communication can be threatening to personal liberties, existing political regimes, and traditional cultures.

As institutions globalize, they not only affect regional traditions but sometimes breed hostility from disaffected citizens, ethnic groups, or persecuted minorities who take anti-globalization and (sometimes) antidemocratic actions to preserve their values (Bello, 2005; Bowers, 2016; Milanovich, 2016; Stiglitz, 2017; Veseth, 2005). In some regions, globalization and its accompanying technologies are viewed negatively as the imposition of "Western" cultural values on indigenous ethnic and religious groups. Changes may also be viewed as monoculturalism, spawning fears that long-held traditions may be wiped out by the technological revolution led by the West. Alternatively, the perceived threat of cultural imperialism is often viewed as an unwelcome challenge to traditional, 
sometimes authoritarian, regimes challenged by techno-changes that could overthrow democracies, dictators, economic elites or monarchies.

In contrast, advocates of Western-style globalization argue that free market policies advance banking reforms, capitalism, democracy, educational opportunity, economic development, gender equality, human rights, property rights, and personal freedoms (Bhagwati, 2004; DeSoto, 2004; Prestowitz, 2006). Globalization also impacts the success or failure of various strategies to achieve commercial, economic, and educational development goals. Advocates point to countries as diverse as Estonia, Finland, New Zealand, the Republic of Korea, and Singapore as examples of nations that have advanced competitively using ICTs in various sectors of their educational systems and domestic economies. ${ }^{1}$

Globalization has also contributed to the rise of multinational corporations (MNCs), huge worldwide conglomerates which operate in many local environments on several continents. Facilities and other assets are located in at least one country other than the home country, and logistics and global management are typically coordinated from a central location. Multinationals such as Apple, Exxon, Nike, and Toyota have annual revenue (sales) that exceed that of most developing nations; this largesse permits them to exert economic and political pressures on "host" governments to make concessions favorable to MNC interests. ${ }^{2}$ In the broader context of globalization, mobile citizens educated in the target countries can help to interpret the cultural responsibilities of MNCs and leverage the advantages of a global reach while balancing the challenges of local impact.

Capitalist free market practices are typically the entry toll to international markets, but this prerequisite has rarely led to changes in political systems. China, for example, has adopted limited free market capitalist reforms, but its single-party political dominance has remained unchanged. The spread of capitalism since the 1970s added 3 billion ambitious new players from developing countries (primarily China and India) who are now able to work, and do so faster and cheaper than workers in North America or Europe (Prestowitz, 2006). In other countries, the limited injection of free market economics has further concentrated wealth and reinforced existing authoritarian, nationalistic, and repressive regimes. Opinions differ, however, about the long-term effects of these opposing mega-trends.

Those who espouse globalization's positive impact claim that access to computers and the Internet of Things (IoT) levels the playing field, promotes equality, and eliminates many past economic constraints on developing countries. Plainly, millions of individual entrepreneurs are 
empowered to transcend national boundaries which once separated individuals and global trade partners. But that does not mean everyone benefits. Jagdish Bhagwati, among others, argues that economic globalization has neither widened income inequality nor increased poverty in poor nations (Bhagwati, 2004). China and India benefit from economic globalization and (perhaps) shed some of their cultural and ideological legacies: developing countries are using education to train highly skilled and tech-savvy workforces that can produce different post-industrial economies in the future.

Despite the many positive results from economic globalization, there is another more sinister side, including restricted access to technology, amplified income inequality, minority suppression, political subterfuge, unemployment, and environmental exploitation. ${ }^{3}$ American economist Joseph Stiglitz challenges positive assessments, arguing that without fundamental changes in banking and financial institutions, and greater sharing of wealth among developed and developing countries, globalization will continue to favor rich countries over poor ones (Stiglitz, 2017). Disruptive changes in global labor markets also tend to destabilize industries and displace workers.

Educational institutions produce the human capital, intellectual energy, and research innovations to power the global knowledge revolution. As more and more individuals are "connected" in some way through internet devices and computer networks, educational institutions assume greater responsibilities for guiding the future of their societies. Schools are not the only engines generating material improvements and economic growth, but are perceived by many as social levelers to redress inequities and remediate job shifts caused by globalization and technology. Concurrently, consumer expectations for high-quality online education, especially in disciplines needed for high-tech workforces, are becoming on-demand, 24/7, and easily accessible.

There are existing gaps in knowledge, loopholes, and transitional challenges which can only be addressed by innovation and the promotion of digital education. Among the most challenging of these issues is job-competency mismatch, which leads to high unemployment and underemployment rates for even college graduates in the fields of science, engineering, and technology. The shift of the job market is from full-time employment to a "gig economy" where individuals are piecing together full-time employment by means of multiple part-time jobs which typically lack benefits. This creates demand for new roles in higher education, including an increased focus on entrepreneurship. The shrinking middle class in the US is raising awareness of unethical and unsustainable business practices, which are also reflected in higher 
education trends and the increasing popularity of careers in fields that emphasize the promotion of social justice and environmental sustainability. These challenges, which begin in academia, also mean that colleges and universities have the social responsibility to produce more competent graduates in high-demand fields, given that innovation and entrepreneurship help to drive sustainable economic development of underdeveloped countries (Grünwald and Heinrichs, 2015).

Traditional academic organizational hierarchies are being challenged from above and below to transform themselves into "more horizontal and collaborative [structures], across lines and within networks that no one had ever thought possible" (Friedman, 2005: 45). This bottom-up, top-down networked organizational structure is facilitated by technology, but antithetical to the traditional centralized management structure upon which most institutions were founded. Although there are vastly differing opinions about the effects of globalization, internet-created horizontal social media networks such as Facebook, Instagram, and Twitter, that did not even exist a decade ago, are accelerating an already expanding demand for global connectedness.

Nearly all major multinationals are American, Japanese, or Western European, including such familiar brands as Apple, Nike, Coca-Cola, Oracle, Shell, Walmart, Toshiba, Honda, and BMW. Advocates for MNCs assert that they create jobs, generate wealth, and improve technology in countries that are in need of economic development. Critics charge that 147 MNCs control 40 percent of global assets and exert too much political influence over host governments. This concentration of power, if unchecked, inevitably leads to exploitation of human and natural resources, as well as contributing to job losses in home countries by outsourcing to cheaper labor markets. Widespread flux in labor markets is a permanent feature of the global economy, generating workforce dislocation and increasing the need for techno re-education. These inexorable mega-trends pose challenges - as well as benefits, opportunities, and risks - for many segments of the US economy, especially the present educational establishment.

\section{GLOBALIZATION AND THE US ECONOMY}

The "modern" reciprocal trade process which began a generation ago has since accelerated due to ten "flattening forces" including the fall of the Berlin Wall in 1989, the dissemination of Windows software, and the public offering of Netscape in 1995 (Friedman, 2005). Contemporary 
trends include the expanded use of artificial intelligence, cellular telephones, computers, fiber optic networks, and a proliferation of open source websites. Although scholars still disagree about its definition, effects, and origins, globalization continues to impact political, economic, and social interactions on a broader scale than ever before.

The apparent catalysts for globalization coincided with the standardization of Microsoft Windows workflow software in the early 1990s, enabling individuals to communicate with others across the office, and collaborate and share information around the world. Following the dissolution of the Soviet Union and the collapse of the Berlin Wall around the same time, Eastern Europe opened up its economies to the rest of the world; within five years, the Netscape web browser was launched, allowing anyone with a computer to access the internet's vast reservoir of online knowledge (Friedman, 2005: 48-55).

These changes prompted another form of communication and information-sharing - the free or open source software movement allowing anyone the ability to upload programs to the internet and improve them. The educational equivalent of this concept is open educational resources (OERs) (discussed in Chapter 4). The free online open source phenomenon Wikipedia was so successful that it threatened the economic viability of traditional printed encyclopedias, most of which have disappeared. (Today, if someone wanted to print the full Wikipedia collection, it would comprise 10000 physical volumes of about 700 pages each and cost $\$ 1$ million.) Textbook publishers have also adapted to the internet with e-publishing. Likewise, Amazon's CreateSpace, Google's Chrome, Mozilla's Firefox browser, Microsoft's Internet Explorer, and Apple's Safari provide stiff competition for traditional publishers. Not only can anyone use the free software, but those who modified the code can sell their own versions so long as they credit the original software and meet certain licensing requirements. Free or "open source" software has created a global industry of computer-savvy individuals who actively contribute to expanding knowledge bases in nearly all disciplines.

Outsourcing has accelerated since the dot-com bust in the late 1990s. Many companies suffered billions of dollars in losses from investing in fiber optic cables that now span the globe. This was a boon for government and private companies in India, which purchased these systems at bargain prices. Many skilled workers from developing countries showed their competence to do complex service work, by first fixing Year 2000 (Y2K) bugs, then receiving contracts for other higher-skill work such as reprogramming computers and helping customers to fix computer glitches at call centers. Offshoring occurs when companies 
move entire factories to less developed countries. Within the context of education, examples that come to mind include hiring external businesses to design course content, hosting learning management systems, or handling logistics such as marketing and enrollment management. Workers are paid less and receive fewer benefits than those working for companies producing similar goods and services in developed economies of North America and Europe (Friedman, 2005: 114-127). For instance, factories producing so-called "American" vehicles are now located in countries such as Mexico where labor costs are lower; paradoxically, "Japanese" cars are produced by American workers in the United States factories where labor costs are lower than in Japan. Instructional design, media production, and content creation are often offshored to places where high-skill labor is cheaper. There is always a concern with quality, however; especially regarding the command of language and appropriate use of cultural references.

Although these global megatrends have led to millions of US manufacturing jobs being outsourced, they have also created "insourcing" opportunities for jobs involving service processing such as supplychaining. With the nearly complete outsourcing of manufacturing industries from the US and the European Union (EU) to emerging nations such as China and Mexico, well-paying jobs have shifted the nexus of political as well as economic power from Europe and North America to Asia and, beginning in recent years, Latin America and Africa. The "just-in-time" inventory control system, also known as supply chain management, enables companies to track products precisely and accurately from manufacturer to supplier to consumer, and know when to replenish products. This technology was developed by Walmart and eliminates the need for warehousing because it traces every single item in stock to ensure constant resupply at retail outlets. ${ }^{4}$ United Parcel Service (UPS) implemented supply-chaining for its package delivery service and now offers additional features to companies through what is referred to as insourcing. Further pushing the world toward globalization is informing: the creation of search engines such as Microsoft's Bing, Yahoo!, and Google, enabling more and more people to access greater amounts of information, products, and services directly for themselves.

The use of big data plays an increasingly important role in education as well, especially with the introduction of free educational content available from Google, Khan Academy, TED Talks, and YouTube. Technology, Entertainment, Design (TED) is a nonprofit organization that gathers outstanding people from a wide range of industries and sectors to share their thoughts in the TED Conference or one of many TED Talks. These talks are uploaded for anyone to watch for free. TED Talks are a 
major source of inspiration for educators who need a morale boost, a discussion starter, or a new perspective. ${ }^{5}$ Their messages can be invaluable for educators who work tirelessly to inspire creativity, motivation, and determination in their students. Big data sets are being collected to inform educators about the effectiveness of instructional strategies, media, and delivery formats for curricular materials.

The final cluster of global flatteners eliminates nearly all barriers to entering global markets. Increasingly less expensive devices can access internet content, providing equal access to educational opportunities across the globe. There are new digital, personal, mobile, and virtual technologies which reduce overheads and enable companies to communicate with employees, no matter where they are physically located, via the internet and mobile networks. Those seeking advanced education have a mobile connection that fits in their pocket and allows them to learn efficiently even when miles away from the source. Smartphones allow everyone to be reachable almost anywhere at any time. The number of mobile subscribers toting smartphones continues to grow with technological advances and less expensive, more powerful devices. However, an apparent artifact of instantaneous communication is increasing distrust of government as well as large social media organizations, and a sharp turn toward trade protectionism and extreme right-wing politics, especially in Brazil, the United Kingdom, and the United States.

The belief that government acts in the best interests of its citizens is being challenged by the spread of globalization, expanding income inequality, hackers, and growing concentrations of wealth in world politics. ${ }^{6}$ As it becomes easier and more profitable to move operations overseas, educators, governments, and political leaders are scrambling to ensure dislocated workers have opportunities for productive employment. Greater numbers of people are being forced to rely on governmental services - including public education, career retraining, retirement options, and unemployment compensation - to avoid being further victimized by international economic competition. In the United States, concerns over job displacement have prompted interest groups, especially labor organizations, to request protectionist legislation and higher tariffs on imported goods.

When US President Bill Clinton took office in 1993, his foreign policy was based on the promotion of free trade. He believed in the democratizing effect of globalization and, to ensure its success, a social safety net was required to guarantee job retraining for those displaced by globalization. The President of the United States may not have absolute power over domestic policy, but the chief executive exerts a significant degree of influence over economic, foreign, and trade policy. President Clinton 
(1993-2001) made some strides with passage of North American Free Trade Agreement (NAFTA) and revisions to the World Trade Organization (WTO), eliminating many trade barriers that existed at the time.

President George W. Bush's post-9/11 policies centered on encouraging the growth of corporations without regard to those American workers who did not have safety nets. Republican victories in many states as well as the US Congress in 2014 slowed government intervention and the maintenance of social safety nets that ensure some job security for displaced workers. President Bush (2001-2009) encouraged subsidies to ensure industry growth in some sectors nationally, but did not aggressively push worldwide economic expansion (Bhagwati, 2004: 128). Conversely, the Bush administration failed to recognize the importance of educational reforms as a means to hold jobs and compete globally.

President Barack Obama (2009-2017) was a staunch ally of labor groups who argued for more job training for displaced American workers. The only way to assure that workers are protected without enacting anti-competitive trade tariffs or import-export restrictions is to provide retraining (safety nets) for those affected by global trends. In his second term, Obama also pursued an aggressive strategy of strengthening trade with Pacific nations, trying to persuade Congress to pass a comprehensive Trans-Pacific Partnership (TPP) agreement between the United States and 11 other nations, excluding China and Russia. The vote was a temporary victory for the Obama administration, Democrats, and multinational corporations which lobbied hard for a trade agreement which challenged China's export dominance, sought lower tariffs and the deregulation of sectors as diverse as agriculture, banking and pharmaceuticals.

One of Donald J. Trump's first policy changes after being elected was to move swiftly to fulfill a campaign promise to repeal the TPP agreement, not yet officially approved by Congress. This policy change was consistent with the Trump administration's nationalistic "America First" economic strategy, which could undercut globalization. Global economies are accelerating and, barring any catastrophic collapse of US leadership, are likely to continue gaining strength. President Trump's proposed tariffs are impacting deficits and sales of products from global organizations. While the initial economic impact of Trump's approach was reflected in a positive stock market trend, over time the true impact of these decisions will be realized. If the impact is negative, the effect on American workers will likely be severe, as there are few remaining safety nets for displaced and underemployed US workers. 
There is no ignoring the fact that the US economy has experienced decades of long-term real wage stagnation and a persistent lack of economic progress. The careers of many able and willing American workers have been cut short, delayed, or diverted by a weak US economic recovery, techno-displacement, lack of competitiveness, and the expansion of multinational corporations in the new global economy. Careers remain in flux as benefits such as healthcare and retirement pensions are being abandoned by companies seeking to avoid long-term costs and commitments to employees. Overemphasis on costeffectiveness and efficiency for the sake of profit has its own inherent shortcomings, eschewing America's most valuable asset: loyal employees. The challenge for educators is to moderate the negative impacts of globalization through policies that encourage economic competitiveness and job growth without sacrificing a generation of naïve students or willing workers.

While the US President possesses great power, it is debatable whether the mega-trend of globalization can be altered by any one individual, no matter how powerful. Arguably, the real power rests in the hands of US multinational corporations, which lack incentives to protect domestic workers or otherwise limit the environmental effects of globalization, which directly affect their bottom line.

\section{FUTURE CHALLENGES FOR EDUCATORS}

Technology will ultimately facilitate the replacement of traditional hierarchical educational control structures with new horizontal networked processes stressing open access, collaboration, decentralization, flexibility, and diversity. During the early stages of this social transformation, education systems have been unable to respond quickly enough to incorporate the computer-internet technological revolution. Despite the future demand for more high-tech workers, and job displacement caused by globalization, formal education systems have remained basically unchanged from those designed in the early nineteenth century. As new technologies evolve, virtual education can help to shortcut the re-education requirements necessary to remain competitive. This is an urgent task, as the share of American workforce jobs that require advanced digital skills training has increased by 70 percent in just the past 15 years, without a corresponding change in basic delivery format of education. ${ }^{7}$ As future mega-trends dictate employment opportunities, online learning technology may be the last best hope for those likely to 
be excluded from the direct benefits of globalization due to lack of technology expertise.

Information technology, communication, and knowledge management continue to permeate learning and teaching processes, albeit slowly prompting educational systems to respond more rapidly to economic and social changes. Innovations in teaching and learning require greater ICT literacy, equality of access, adapting learning systems to students' needs, internet integration, personalized learning, and additional efforts to overcome faculty resistance.

\section{Achieving ICT Literacy}

The importance of ICT literacy among the general student population is also growing with the greater dependency on technology. The massive amount of information available to learners creates new challenges for both faculty and students to identify real and relevant information and use it to acquire knowledge. Students need to know that textbook learning alone will not address issues that they are likely to face in their careers. Information-gathering as well as participation in politics, business, and even daily communications rely more on social media skills, access to the internet, and smartphones. Many countries are recognizing the importance of ICT literacy and are now incorporating computer science and technology into their primary and secondary school curricula.

Online discussions are becoming more common as a means to encourage communication and learner engagement at all levels. Students appreciate the flexibility and direct access via email to instructors. Online literature discussions have great potential for fostering independent literacy skills, strengthening communication, and building a sense of community, rather than engaging in traditional in-class reading and responding.

\section{Closing Digital Divides}

One of the primary goals of education is to prepare people to be productive citizens; an important component is to recognize the value of access and equality of opportunity. Among the more serious criticisms of e-learning as well as traditional education is the problem of inequality of internet access, especially in economically underdeveloped urban and rural areas (see Chapter 2). The once-heralded "American Dream" that everyone can enter the competition of life on an equal footing and, with hard work, have an equal chance to succeed, has morphed into something 
much less egalitarian. Education used to be the vehicle to achieve economic success. However, in e-learning - as with society - the problem of unequal access to computers and other technologies has become more severe. An income gap between rich and poor, black and white, male and female, Hispanic and Asian, already exists for those who do not have access to a computer at home. Public libraries and schools in some regions have begun to provide computer access but, by themselves, public places cannot close the inequality gap. President Obama recognized the problem and called for a concerted national effort to close the digital divide. His administration initiated a program called ConnectED (discussed in Chapter 5) through the US Department of Housing and Urban Development to bring internet broadband access to 275000 low-income households.

Digital learning is unlikely to replace traditional schooling for those with the economic resources to pursue full-service degree programs. Future schooling is likely to offer several tracks, combining virtual learning with traditional schooling for a hybrid learning approach to achieve the vision of lifelong learning (see Chapter 2). Working students seeking upgraded skills necessary for them to remain competitive will have more opportunity to balance career and family responsibilities with online learning. In the information age, the key to success is not only how much one learns in school, but also whether or not one has learned how to learn, and continues learning throughout life. Online learning can fill a need for continuous re-education after graduation, and serve to equalize educational opportunities and distinguish levels of quality in the information we receive.

\section{Improving Future Employment Opportunities}

Digital learning addresses the need to retrain workers in industries that have shifted jobs offshore in the wake of globalization. The best strategy to help workers avoid being outsourced is for governments to make a commitment to higher education. Displaced workers are going to have to be more adaptable, and retrain to fit into new situations as conditions change. Although job markets have shifted, job growth in some sectors is improving, and new sectors are being stimulated through multiple types of online training to meet critical labor shortages. ${ }^{8}$ This strategy does not rely on the federal government, as does unemployment compensation, but provides a means to continue working in the rapidly changing technology-driven global economy. Now, more than ever, as US factories close and industries move overseas, investment in education and job 
training are required to ensure employability and mitigate the negative impact of economic globalization on the US economy.

\section{Internet as Classroom}

Prior to the internet revolution, the learning environment in schools was classroom-based and passive. In a mass one-size-fits-all schooling environment, teachers taught large numbers of students in a restricted timespan; lecturing is the most common method used to facilitate this goal, and homework is the go-to reinforcement to ensure students are absorbing the information. Education psychologists, however, have long suggested that active and stimulating learning is a better method (see Chapter 8). Part of the problem stems from accountability and assessment: it is easier to account for lecture attendance and grade objectively, than it is to deploy different approaches to teaching. Guiding a student's active engagement is likely to lead to a greater variety of activities, forcing teachers to develop flexible methods for assessment that allow for rewarding diverse approaches. Given the limited time and lack of preparedness for this type of activity, teachers are more likely to choose a standardized approach. As a result, progress in pedagogy reform is generally slow, and new learning methods such as inquiry-based or problem-based learning have been sparse at best. With the introduction of new learning technologies, the range of choices for course delivery has expanded.

Students taking courses from a virtual school with an independent method of delivery are similar, but not the same, as those who are being homeschooled by parents or who take a traditional correspondence course, only facilitated by more technology-skilled faculty. Homeschooling offers a cheaper alternative for parents who would previously have had to teach, or hire a tutor to come to their home, and pay for all learning materials. In 2016, 1.7 million or about 3.3 percent of all children were being homeschooled in the US. ${ }^{9}$ Most students being homeschooled are middle and upper-income Caucasians whose parents, for a variety of reasons, are wary of government-run public schools. Homeschools remain relevant as long as students are enrolled, parents are participating and not misusing this option. However, it is unlikely that homeschooling will disappear with the convenience of online courses, or the broader availability of public and virtual school options.

The virtual experience also attracts independent students because they must assume responsibility for designing their own learning progress plans. Thus, the independent student is essentially motivating themself, with only minimum involvement from a teacher. The online virtual 
school provides the curriculum materials that will be used by the student throughout the course. Virtual learning promotes a more comfortable environment for students to share their thoughts with their classroom peers. A common misconception about online teaching is that the teacher is mainly involved at the design stage, when the materials are created, and perhaps provides feedback on some assignments that cannot be graded automatically. While this may be the case for some programs and institutions, it is certainly not a necessity, nor is it built in to online learning. This pedagogical approach is in fact largely independent of the mode of delivery; students may be allowed to determine and shape their own path, or be required to follow detailed directions and meet very specific criteria.

\section{Personalized Learning}

Classroom environments which utilize digital personalized learning are certainly more flexible and attractive to more independent, adaptive learners, but at the same time they can foster a comfort zone for all participants to share ideas. The design of the course in alignment with the determined outcomes is critical, as is the involvement and accessibility of the instructor. Flexibility of time and place are valuable assets of online learning, but they alone will not enhance the educational experience. William Eggers (2005) asserts that the use of technology in classrooms will transition education from a "One-Size-Fits-All" to "My Size Fits Me" learning environment. He argues that most schools provide the assembly line form of education, under which some students fall behind the curriculum, while others are unchallenged by the level at which materials are presented. Experienced teachers will immediately recognize this dilemma. With the introduction of personalized courses, students have expanded opportunities to customize their learning process. Faculty can keep track of each student's progress, improving their ability to assess every individual's weaknesses and strengths. Children obviously do not learn at the same rate, but there is some infrastructure for advanced courses even at the grade school level. In schools where virtual learning is a reality, students seem to be satisfied with the flexibility and individual subject of interest focus that e-learning offers. ${ }^{10}$

One of the projects launched by the Chan Zuckerberg Initiative in the US is Summit Public Schools, founded in 2003. At the core of its approach is the goal to enable high school students to graduate with the skills to succeed in life, including the fundamental ability to continue lifelong learning. Through personalized learning, students can engage with subject matter at their own pace, enabling them to identify the path 
that is most compatible with their needs and interests. Rather than being given a list of tasks and objectives, students are exposed to real-world problems to solve, working both individually and in teams with the support of the teacher. Through this process they learn not only how to tackle specific problems, but also how to find and use resources, and how to leverage the contributions of peers and subject matter experts; which are precisely the skills they will need to succeed in their personal and professional lives after they graduate.

\section{ACCEPTANCE OF VIRTUAL LEARNING}

One of the challenges for implementing a virtual school is the training of teachers - most of whom have only experienced traditional, face-to-face teaching - to become virtual educators. Many faculties are reluctant to go "back to school" to learn how to teach their curriculum effectively with the help of advanced technological devices. Therefore, the social context in which a mass technology adoption must take place has to be agreed to by the stakeholders involved. Teachers will have to go back to school to learn how to orient their students in this new technological adventure. Governments can assist information technology implementation processes in public schools so that adequate adaptation and support are guaranteed. Not only do governments have to reassure students and teachers that technology will not end their careers, but they must also guarantee to provide training on how to use it effectively. Therefore, it is crucial for e-learning programs and processes to be constantly updated to ensure that the virtual method is both effective and efficient in a long-term period. Most of all, teachers and instructors will have to accept the fact that technology is available to help them teach, not to compete with or replace them.

\section{Online Education Accreditation and Standards}

Consumer protection in higher education has historically been accomplished primarily through accreditation, the process by which colleges, through nonprofit agencies, are examined by members of other colleges who certify that they meet minimum standards of quality. In other words, accreditors are charged with the difficult task of certifying that a college department or program is educationally sound. State approval or regional accreditation are important with respect to how the affected public views virtual schools' credibility. Accreditation reassures parents and students that a particular online course or degree is trustworthy, and that online 
learning will be respected in the job-sphere. This will increase the probability - but not guarantee - that the curriculum taught by virtual methods can offer comparable results for students' learning processes. Student feedback, whether through formal evaluations or through informal forms such as "rate-my-professor," can also provide checks and balances. Especially in online education where competition is fierce due to global access, professors and institutions are under increased pressure to perform well on independent online platforms designed to level the playing field.

Rankings and reviews actively shape the behavior of online consumers (including consumers of educational services), and student profiles and expectations are very different from what a traditional brick-and-mortar institution might expect (see Chapter 14). Since there are both privately and publicly funded virtual learning systems and education programs offered in the United States, how can students know which are accredited and successful, and which are not? The Global Learning Council led by Carnegie Mellon's president is a council of educators devoted to creating standards for all virtual learning systems, in order for prospective students and teachers to know which programs they want to enroll in and teach. The Global Learning Council is evaluating existing learning systems and creating a set of standards for all future systems to abide by in order to ensure successful online learning programs. However, a standard system, which uses awards to rate successful virtual learning systems, does currently exist. The Sloan Consortium has created Effective Practice Awards Honoring Innovation in Online Education, which recognize and honor innovations in online learning applied to a wide range of disciplines. These awards are used to inspire and reward different virtual learning systems and promote more companies and colleges to invest in online educational resources. This recognition of successful virtual learning systems is important for the future of American education because it causes more investment to be made in online resources, which is essential for any country's ability to compete with educational systems around the world.

The use of established standards for American virtual learning systems are essential for students to choose which online programs they wish to enroll in. But it will take time for organizations such as the Global Learning Council, the Sloan Foundation, and others mentioned in this book to determine what these standards will be. Since these standards have not been explicitly stated, it is difficult to determine which is the most effective virtual learning system.

Governments can promote virtual learning, especially for those who cannot afford a traditional private school or are located in remote areas. 
Rural residents can greatly benefit from having internet access and taking courses online; they can overcome digital barriers and will not fall behind in the race for an education that is accepted in the marketplace.

\section{Adopting E-Learning}

Once a school decides to offer e-learning it has to: (1) calculate the initial costs of the transition from traditional learning to virtual learning; (2) adopt the philosophy of a virtual learning community; (3) provide students with email, online chat rooms, and other internet resources along with traditional classroom materials to teach students; and (4) offer virtual classes to meet the needs of all grade levels and for continuing students.

Increasing numbers of organizations and educational institutions use technologically assisted learning communities to encourage knowledgesharing. However, simply grouping people together and chatting online cannot accomplish this task. The explosion of web-based technology led to the increased volume and complexity of knowledge, which stimulates the proliferation of virtual learning environments (VLEs), defined as "information technology-based cyberspaces in which individuals and groups of geographically dispersed learners accomplish their e-learning goals" (Chen et al., 2009: 136). Therefore, whether learners can share knowledge by providing ideas and helping others resolve problems over the internet becomes critical in enhancing learning performance. Consequently, the participants of learning activities in virtual learning need to understand precisely what knowledge will fulfill their needs and hone their skills to find relevant knowledge for a given purpose.

As online educational alternatives develop and expand, they should be accompanied by quality assurance, significant improvements in delivery methods, and eventually cost reductions. Simply reproducing existing material in electronic format will not enhance learning. Creating virtual online courses demands rigorous planning as well as imagination to capture their true potential. With any teaching and learning activity, a critical evaluation of the effectiveness of existing practice provides insights into what works and what does not. Adopting this experimental strategy will help to ensure that courses within the virtual learning environment will improve access to a customized curriculum and enhance the quality of learning.

Adaptive pedagogy is not limited only to day-to-day learning: advancements in online learning have made it possible to continue education uninterrupted through pandemics or natural disasters. For example, during the severe acute respiratory syndrome (SARS) outbreak in 2003, 
most Southeast Asian countries closed schools to prevent transmission of the disease in a crowded environment. Since then, Singapore began a systematic approach to prepare for continuity of learning in case of disruption via natural disaster. Although Singapore schools still hold face-to-face classes throughout the year, they also have an e-learning week once a year to prepare for the eventuality of a typhoon or other reasons for school closures. This prepared model was put into use during the 2009 outbreak of the H1N1 virus, when two secondary schools needed to close for a week after their teachers tested positive for the virus. Even in extreme cases, e-learning enables students to move on unflinchingly in pursuit of knowledge.

\section{Equalizing Learning Opportunities}

Although the widespread use of technological tools may look promising, there are some less obvious challenges ahead. The use of new classroom technology can cause negative distractions that can detract from the value of technologies for educational purposes. First is the diversion brought by the new technologies. Students are already being criticized for using cellphones and texting in class, bringing about disciplinary issues as well as concerns about lower attention spans. While technological adoption in schools is generally seen as positive, many primary and secondary schools cannot afford to have a "one-to-one" policy of a laptop for every child, even with the price declines in recent years. This leads to a situation where multiple users are grouped around a single computer, leading to a "too many cooks in the kitchen" experience that adds to teachers' classroom duties and almost encourages distracting behavior. It is still very costly to maintain and update classroom computers. Even when students or schools can afford to equip every student with a computer, it is difficult for teachers to know whether they are using the computer to take notes, do class work, or just "Facebooking." Public opinion on this issue is split 50:50. When asked the question, "Should students' computers be monitored by teachers?", half of all parents say "Yes" and the other half "No." Almost all high schools now have software to block social media sites to help limit such distractions.

It might not be as convenient, but there are opportunities to use the internet without owning a device. Android is the fourth most supported operating system (OS) on many websites' lists, behind Windows and OSX, but usually taglines place it right after its bigger brother Linux. This is relevant because "good" Android devices are selling for under $\$ 100$, certainly far more affordable than a traditional laptop or desktop computer. In addition, Raspberry has launched its second iteration of the 
$\mathrm{Pi}$, a $\$ 35$ computer with adequate hardware even by modern standards. There are also other affordable devices for reading books, such as Barnes \& Noble Nooks and Kindle Readers.

\section{Overcoming Resistance to Change}

Schools are places to teach the next generation, but current faculty occupants are inherently more skeptical about changes (see Chapter 3). In the 1950s, a group of scientists and educators proposed a new curriculum which focused on scientific thinking and methods combined with hands-on experience, to better facilitate learning. It was abandoned in less than ten years due to teachers' inability to understand it and the extra work required by educators to support it. A similar problem exists with advances in virtual learning, pitted against the same resisting factors. Critics of virtual learning within the educational establishment make some very valid points against it: online learning lacks vital studentteacher interaction and, some argue, does not provide sufficient motivation for students to learn on their own. These issues are not inherent attributes of online learning, but rather the results of inadequate training, hasty implementation, involuntary conversions from traditional to online teaching, unrealistic enrollments, and overloaded faculty schedules. They can be fixed, and should not be used to discredit the effectiveness of online teaching and learning.

We learn more than just academic knowledge from schools. If we are to achieve goals such as equal access to quality education for the next generation of learners via the internet, we may lose the chance to learn the interpersonal skills which play a more significant role in most lives than do algebra and literature. Just as Robert Fulghum suggests, the things we must learn when we grow up are: "share everything, play fair, don't hit people, put things back where you found them, clean up your mess, wash your hands before you eat, and flush"; all social behaviors learned in kindergarten, but not in front of a computer (Fulghum, 1990). There are other subjects, such as physical education, arts, and music, that have traditionally been learned by practice and may not translate well into virtual education. However, there are increasing numbers of examples for effective online yoga instruction, personal trainers, as well as music lessons, that leverage the use of the online environment to maximize the opportunity of direct instruction and offset practice, repetition, and even technical aspects of learning that can be monitored programmatically (that is, pitch correction, tempo, and so on). ${ }^{11}$

The convergence of global mega-trends has increased flexibility, enhanced receptivity to customer service, spurred open-sourcing, and 
accelerated the need for lifelong learning and just-in-time education. The techno-genie is out of the bottle and is not likely to return.

\section{NOTES}

1. Recent competitiveness indices show that the US is losing its innovative advantage to other nations - such as the Republic of Korea, Finland, and Singapore - with very different political regimes and economic development strategies. See, for example, https://www. weforum.org/events/world-economic-forum as well as individual degrees and programsannual-meeting-2018.

2. Apple, Inc. has a market value in excess of $\$ 1$ trillion ( $\$ 1000$ billion), exceeding the gross national products (GNP) of all but 16 countries, giving the company extraordinary power to pressure suppliers to drive down costs in pursuit of lower prices (and higher profits). In many instances, MNCs are so thoroughly entangled in the laws of different nations that they become too difficult for any one country to regulate. Governments often turn a blind eye to exploitative labor practices, environmental degradation, and human rights violations. Meanwhile, MNCs keep pace or outperform national corporations, and are among the primary providers of jobs in economically underdeveloped nations. They seek to influence host governments in a variety of ways, many of which benefit themselves and their shareholders.

3. See also case studies on Shell Oil Company in Nigeria and Chevron in Ecuador: Royal Dutch Shell Oil Company's nefarious affiliation with dictatorial regimes in Nigeria is one such example, and Chevron-Texaco's massive oil spill in the Amazon basin is another.

4. As the largest private employer in United States and the world's largest retailer, Walmart also cut out the middleman and purchases products directly from companies in developing nations to further reduce costs.

5. For example, see http://www.edudemic.com/10-best-ted-talks-of-2014-for-educators/.

6. http://www.npr.org/people/131724812/scott-neuman.

7. https://www.brookings.edu/research/digitalization-and-the-american-workforce/.

8. As of July 2018, there were 6 million unfilled jobs in the United States. "The US Labor Shortage in Reaching a Critical Point," CNBC, July 2018, http://wwwcnbc.com/2018/07/ 05/the-us-labor-shortage-is-reaching-a-critical-point.html.

9. https://www.nheri.org/homeschool-population-size-growing/.

10. A study among the students who were enrolled in a fully online graduate early childhood education program at one of the universities in New Jersey found that "students were satisfied with the online courses and enjoyed the virtual learning experience" (Shin and Lee, 2009: 32-33). Students expressed that flexibility and being able to study around their work and personal schedules is a major advantage of attending online classes.

11. The son of one of the authors who lives in Florida took private online mandolin lessons from a teacher in Boston, MA. He would never have had the opportunity to learn from an online instructor if it were not for access to web technologies.

\section{KEY TERMS}

accreditation 26

American Dream 22

Android 29

big data 18

cultural imperialism 13 
digital divide 23

free trade 19

global flatteners 19

globalization 12

Global Learning Council 27

gross national product (GNP) 31

homeschooling 24

Honoring Innovation in Online Education 27

hybrid learning 23

ICT literacy 22

import-export restrictions 20

independent students 24

internet access device 13

Internet of Things (IoT) 14

knowledge management 12

multinational corporations (MNCs) 14

North American Free Trade Agreement (NAFTA) 20

personalized learning 22

profit 21

protectionism 19

stakeholders 26

supply chain management 18

TED Talks 18

trade tariffs 20

Trans-Pacific Partnership (TPP) 20

virtual learning environments (VLEs) 28

World Trade Organization (WTO) 20 